\title{
Study of utilization of antenatal care services in tribal area of Thane district
}

\author{
Kalpalata Abhiman Bhaisare ${ }^{1 *}$, Dasi H. Rao ${ }^{2}$, Gautam Marotrao Khakase ${ }^{1}$ \\ ${ }^{1}$ Department of Community Medicine, Shri Vasantrao Naik Government Medical College, Yavatmal, MS, India \\ ${ }^{2}$ Department of of Community Medicine, Lokamanya Tilak Municipal Medical College, Mumbai, MS, India
}

Received: 27 January 2015

Accepted: 16 February 2015

\section{*Correspondence:}

Dr. Kalpalata Abhiman Bhaisare,

E-mail: kalpalata06@gmail.com

Copyright: $\odot$ the author(s), publisher and licensee Medip Academy. This is an open-access article distributed under the terms of the Creative Commons Attribution Non-Commercial License, which permits unrestricted non-commercial use, distribution, and reproduction in any medium, provided the original work is properly cited.

\begin{abstract}
Background: Many health problems among pregnant women are preventable, detectable or treatable through visits to health facility before birth. This enables women to receive important services, such as tetanus vaccinations and screening and treatment for infections, as well as potentially life-saving information on warning signs during pregnancy. ${ }^{2}$ The objective of this study is to understand the current status of utilization of maternal health services in rural area by elucidating the various factors influencing the use of these services.

Methods: It is a community based, cross sectional study carried out in a primary health centre in tribal area of Thane district.

Results: $93 \%$ women received ANC care for 3 or more than 3 times. $73 \%$ women received recommended antenatal care. $68 \%$ women received ANC care exclusively from public health facility.

Conclusions: Inspite of implementation of various programmes like Janani Suraksha Yojana, Matrutva Anudan Yojana and NRHM in the area percentage of registration during first trimester was less. There was lack of awareness and motivation in study subjects to come on their own to PHC for early registration of pregnancy. Though the coverage of ANC services was good it was not of good quality.
\end{abstract}

Keywords: Antenatal care, Maternal health, Registration of pregnancy, Tribal area, Utilization

\section{INTRODUCTION}

MDG 5 focuses on improving maternal health. ${ }^{1}$ A substantially lower proportion of pregnant women receive the standard set of four visits recommended by WHO and UNICEF. Many health problems among pregnant women are preventable, detectable or treatable through visits with trained health workers before birth. These enable women to receive important services, such as tetanus vaccinations and screening and treatment for infections, as well as potentially life-saving information on warning signs during pregnancy. ${ }^{2}$ Antenatal care is an opportunity to promote the benefits of skilled attendance at birth and to encourage women to seek postpartum care for themselves and their newborns. ${ }^{3}$ Little is known about the current magnitude of use and factors influencing the use of these services in Maharashtra \& particularly in this tribal area.

Objective of study: 1) To study the current pattern of utilization of antenatal care services in tribal area. 2) To study factors influencing utilization of antenatal services in study area.

\section{METHODS}

This was a community based, cross sectional study, carried out from May 2008 to April 2009 period, in a primary health centre in tribal area of Thane district which is a rural field practice area for Seth G.S. medical 
college, Mumbai and serves a population of 30745. All the married women who have delivered a baby prior to 3 months, residing in study area were included. Unmarried mothers, divorcee and nonresident women of study area were excluded from the study. Ethical clearance was obtained from ethics committee of Seth G.S. medical college, Mumbai.

Sampling technique: Multistage with simple random sampling. First stage: all 8 sub centres were selected. Second stage: villages in each sub centre were randomly selected. Third stage: married women who have delivered a baby 3 months prior to study were randomly selected.

Sample size calculation: The total population of PHC was 30745 . Total live birth in previous year $=639$, Birth rate of PHC was $21 \%$.

Expected No. of pregnancies was calculated for each sub centre using formula - Expected number of ANCs in one year $=$ Birth rate $\mathrm{x}$ population $/ 1000+10 \%$ (pregnancy wastage). ${ }^{4}$ Total expected no of pregnancies in PHC in a year was $831.10 \%$ of expected No. pregnancies in a year were taken as a sample from each sub centre. So average of all sub-centres $=83$. Considering nonresponse of study subjects' additional sample of $15 \%$ was taken. So $15 \%$ of $83=12.45$. Therefore, $83+12.45=95.45$.

So, on an average 100 was taken as a sample size.

Table 1: Sample size - Anganwadi report.

\begin{tabular}{|c|c|c|c|c|}
\hline $\begin{array}{l}\text { Sub } \\
\text { centre }\end{array}$ & $\begin{array}{l}\text { Popul- } \\
\text { ation }\end{array}$ & $\begin{array}{l}\text { Birth } \\
\text { rate of } \\
\text { sub } \\
\text { centre }\end{array}$ & $\begin{array}{l}\text { Expected } \\
\text { No. of } \\
\text { pregnancies }\end{array}$ & $\begin{array}{l}10 \% \text { of } \\
\text { expd. No. of } \\
\text { pregnancies }\end{array}$ \\
\hline A & 5091 & 23.96 & 134.17 & 13.41 \\
\hline B & 4101 & 28.52 & 128.65 & 12.86 \\
\hline $\mathrm{C}$ & 4439 & 27.48 & 134.17 & 13.41 \\
\hline $\mathrm{D}$ & 5084 & 21.63 & 120.95 & 12.09 \\
\hline $\mathrm{E}$ & 3243 & 25.9 & 92.38 & 9.23 \\
\hline $\mathrm{F}$ & 2739 & 22.63 & 68.17 & 6.81 \\
\hline $\mathrm{G}$ & 3164 & 23.7 & 82.47 & 8.24 \\
\hline $\mathrm{H}$ & 2884 & 22.19 & 70.38 & 7.03 \\
\hline $\begin{array}{l}\text { Total } \\
\text { populati } \\
\text { on of } \\
\text { PHC }\end{array}$ & 30745 & $\begin{array}{l}24.50 \\
\text { (avg. } \\
\text { of all) }\end{array}$ & 831.34 & 82.93 \\
\hline
\end{tabular}

Anganwadi from pada or village randomly selected from a subcentre was visited. Rapport was built with Anganwadi workers. no \& details of women who had 3 months old baby was taken from Anganwadi register and houses of women were visited with the help of Anganwadi assistant. Interviews of women were conducted after taking informed consent. Data was collected by using standard, validated questionnaires based on District Level Household Survey (DLHS) Reproductive and Child Health (RCH) Round II, Phase
II, 2004 Woman's Questionnaire. ${ }^{5}$ It was suitably modified to meet objectives of study and was pilot-tested.

Statistical analysis was done by using SPSS version 16 software. Descriptive statistics for Socio-demographic factors done. Cross tabulation to find association between different variables by using Chi-square test wherever applicable. $\mathrm{P}$ value of $<0.05$ was taken as significant.

\section{RESULTS}

Almost half of women $(51 \%)$ were from scheduled tribes, $36 \%$ belongs to $\mathrm{OBC}$ and $3 \%$ scheduled castes. $75 \%$ women belong to $18-25$ years age group. Only $10 \%$ women were working. $70 \%$ women were literate. Out of literate women, 28 received primary education while 35 received secondary education. Only 7 women received higher secondary education. 49 respondents were primipara and 45 were multipara. Only 6 women were grand multipara. All women were registered for ANC care at sub centre or PHC during pregnancy. 58 women were registered during first trimester. 37 women were registered during second trimester. Only 5 women were registered during third trimester. 72 were registered by ANMs during their visit to village Anganwadi. Only 13 women registered directly at PHC. Only 12 women got registered at sub centre. 8 women were having history of abortion at previous pregnancy while 6 women were having history of stillbirth.4 women were having history of death of baby within 2 month of delivery at previous pregnancy. 88 study subjects were aware while 12 were not aware of ANC services at PHC. Only 60 women utilize ANC services at PHC. $68 \%$ women received ANC care exclusively from public health facility while $32 \%$ women in addition to PHC or sub centre also visited to private hospitals for ANC check-up. 99\% women received inj. TT. 73 women received recommended antenatal care and 27 women did not receive it. Only 9 women were given referral to higher centre for some or other reason during antenatal care. Out of 9 women given referral, reason for referral in 6 women was swelling over legs alone or along with some other reason like previous history of Pregnancy Induced Hypertension (PIH) or raised blood pressure. Reason for referral in 3 women was history of abortion, PIH with anaemia, elderly primi respectively.

Height was measured in only 12 respondents. 45 women were asked for swelling over legs and only 39 women were examined for signs of edema. Blood group was tested in only 37 women. Only 22 women were referred to ICTC for HIV \& VDRL. Only 38 women were advised for ultrasonography (USG). Only 29 women received information about contraception. Only 48 women received information about danger signs of pregnancy. $32.8 \%$ women who utilized ANC services at PHC were illiterate. $67.2 \%$ women who utilized ANC services at PHC were literate. The association between educational status of women and utilization of ANC services was found to be statistically significant.51.9\%women who did 
not received recommended ANC care had institutional delivery. $87.7 \%$ women who received minimum recommended ANC care had institutional delivery. Majority of women who received minimum recommended ANC care had institutional delivery as compared to those women who did not received recommended ANC care. The association between utilization of minimum Recommended ANC care and place of delivery was found to be statistically significant.44.4\% women from middle class utilized ANC services. $67.1 \%$ women from lower class utilized ANC services. Almost two third women from lower class utilized ANC services at PHC as compared to women from middle class. The association between socioeconomic class of study subjects and Utilization of ANC services was found to be statistically significant. 30 $\%$ women were not satisfied with ANC services, reason for same in 9 women was long waiting time while in another 8 women it was long waiting time along with other cause like bad behaviour of staff, non-availability of medicine. While total 12 women answered, behavior of staff was not good and total 12 women answered that proper care is not given at primary health centre in addition to some other reason.

Table 2: Distribution of study subjects according to antenatal care service elements received.

\begin{tabular}{|c|c|c|c|}
\hline Antenatal care service elements & $\begin{array}{l}\text { Performed } \\
\text { in study } \\
\text { subjects }\end{array}$ & $\begin{array}{l}\text { Not performed } \\
\text { in study subjects }\end{array}$ & Total \\
\hline Asked about h/o of complications & 36 & 64 & 100 \\
\hline Asked about chronic illness & 37 & 63 & 100 \\
\hline Asked about drug abuse/any medications & 36 & 64 & 100 \\
\hline Pallor checked & 55 & 45 & 100 \\
\hline Recorded blood pressure & 77 & 23 & 100 \\
\hline Measured weight & 91 & 9 & 100 \\
\hline Measured height & 12 & 88 & 100 \\
\hline Examined for signs of oedema & 39 & 61 & 100 \\
\hline Asked for signs of oedema & 45 & 55 & 100 \\
\hline Measured Fundal height & 72 & 28 & 100 \\
\hline Heard Foetal heart sounds & 65 & 35 & 100 \\
\hline Examined for foetal position\& presentation & 68 & 32 & 100 \\
\hline Blood test done & 77 & 23 & 100 \\
\hline Advised Blood group \&Rh typing & 37 & 63 & 100 \\
\hline Urine test done & 73 & 27 & 100 \\
\hline Referred to VCTC for HIV \& VDRL & 22 & 78 & 100 \\
\hline Advised USG & 38 & 62 & 100 \\
\hline Administered TT injection & 99 & 1 & 100 \\
\hline Advised regarding nutrition & 74 & 26 & 100 \\
\hline Advised about Rest & 66 & 34 & 100 \\
\hline Advised about personal hygiene & 69 & 31 & 100 \\
\hline Advised about exercise & 21 & 79 & 100 \\
\hline Advised to avoid alcohol/tobacco & 43 & 57 & 100 \\
\hline Explained danger signs & 48 & 52 & 100 \\
\hline Explained importance of regular health check ups & 83 & 17 & 100 \\
\hline Explained importance of IFA tablets & 71 & 29 & 100 \\
\hline Explained to avoid heavy work\& jerky travel & 67 & 33 & 100 \\
\hline Told about exclusive breast feeding & 57 & 43 & 100 \\
\hline Told about child immunization & 59 & 41 & 100 \\
\hline Told about contraception & 29 & 71 & 100 \\
\hline Advised regarding place/person of delivery & 94 & 6 & 100 \\
\hline Reminded of next visit & 46 & 54 & 100 \\
\hline Asked client if she has any questions & 11 & 89 & 100 \\
\hline
\end{tabular}


Table 3: Association between age and utilization of Recommended ANC care.

\begin{tabular}{|llll|l|}
\hline \multirow{2}{*}{$\begin{array}{l}\text { Age of study } \\
\text { subjects }\end{array}$} & \multicolumn{3}{l|}{$\begin{array}{l}\text { Recommended } \\
\text { ANC care }\end{array}$} & Total \\
\cline { 2 - 5 } & & No & Yes & \\
\hline \multirow{2}{*}{ 18-25 years } & $\mathrm{N}$ & 16 & 59 & 75 \\
\cline { 2 - 5 } & $\%$ & $21.30 \%$ & $78.70 \%$ & $100.00 \%$ \\
\hline $\begin{array}{l}25 \text { \& above } \\
\text { years }\end{array}$ & $\mathrm{N}$ & 11 & 14 & 25 \\
\hline \multirow{2}{*}{ Total } & $\%$ & $44.00 \%$ & $56.00 \%$ & $100.00 \%$ \\
\hline
\end{tabular}

$\mathrm{X}^{2}$ : 4.888; df: 1 ; $\mathrm{P}$ value: $<0.05$ Significant

Table 4: Association between education and utilization of Recommended ANC care.

\begin{tabular}{|lllll|}
\hline \multirow{2}{*}{$\begin{array}{l}\text { Education of } \\
\text { study subjects }\end{array}$} & \multicolumn{4}{l}{ Recommended } \\
& & No & Yes & Total \\
\multirow{2}{*}{ Illiterate } & $\mathrm{N}$ & 12 & 18 & 30 \\
\cline { 2 - 5 } & $\%$ & $40.00 \%$ & $60.00 \%$ & $100.00 \%$ \\
\hline \multirow{2}{*}{ Literate } & $\mathrm{N}$ & 15 & 55 & 70 \\
\cline { 2 - 5 } & $\%$ & $21.40 \%$ & $78.60 \%$ & $100.00 \%$ \\
\hline \multirow{2}{*}{ Total } & $\mathrm{N}$ & 27 & 73 & 100 \\
\cline { 2 - 5 } & $\%$ & $27.00 \%$ & $73.00 \%$ & $100.00 \%$ \\
\hline
\end{tabular}

$X^{2}$ : 3.675; df: 1; $P$ value: $<0.05$ Significant

\section{DISCUSSION}

Uterine The mean age of women was 23.62 years. Majority (75\%) of women belongs to $18-25$ years age group, a finding similar to J. Yuvaraj et al. ${ }^{6}$ The age of marriage was ranging from 14 to 23 years. The mean age at marriage was 18.41 years, late than (16.4 years) NFHS-3 findings ${ }^{7}$ and early to findings by $(19.8 \pm 3.6$ years) S. P. Zodpey et al. ${ }^{8}$ The range for age at birth of first child was 17 to 32 years. The mean age at birth of first child was 20.64 years, which is slightly higher than national average according to (19.3 years) NFHS III. ${ }^{7} 58$ women were registered during first trimester which is high as compared to findings by $(30 \%)$ C. S. Metgud et al. ${ }^{9} 37$ women were registered during second trimester. Only 5 women were registered during third trimester, similar findings seen by $(5.38 \%)$ C. S. Metgud et al. ${ }^{9}$ Only $22.9 \%$ of expected antenatal mothers were registered in a study by Loveleen et al. ${ }^{10}$ Almost $100 \%$ of women had at least one ANC visit during pregnancy a finding similar to that of Toan K. Tran et al. ${ }^{11}$ and higher as compared to findings by $(87 \%)$ Emilia Goland et al. ${ }^{12}$ While $50.8 \%$ women never had antenatal check-ups in a study by Rajesh Gupta et al. ${ }^{13}$ In present study, 93\% respondents received 3 or more antenatal check-ups. This is higher compared to, $(42.8 \%)$ NFHS-3 data, ${ }^{7}(80.4 \%)$ DLHS-3 Thane district data, ${ }^{5}(58.4 \%)$ S. P. Zodpey et al., ${ }^{8}(61 \%)$ E. Materia et al., ${ }^{14}(41.46 \%)$ Sahni B et al. ${ }^{15}$
$75 \%$ study subjects received and consumed IFA tablets for 3 or more months duration. This is fairly higher as compared to $(30.5 \%)$ NFHS-3 and state figures, $(35.7 \%)$ S. P. Zodpey et al., ${ }^{8}(32.62 \%)$ Sahni B et al., ${ }^{15}(63 \%)$ Bbaale E et al. ${ }^{16} 80 \%$ women received IFA tablets in a study by Toan K. Tran et al. ${ }^{11} 99 \%$ women received inj. TT higher as compared to finding ( $91.7 \%$ ) by Toan K. Tran et al. ${ }^{11}$ and $(50 \%)$ Bbaale E et al. ${ }^{16} 73$ respondents received "minimum recommended antenatal care". higher compared to, (33.6\%) S. P. Zodpey, ${ }^{8}(29.12 \%)$ Sahni B et al. ${ }^{15}$ Only 38 women done USG which was very low compared to $96.8 \%$ in a study by Toan K. Tran et al. ${ }^{11}$

$18(60.0 \%)$ illiterate women received minimum Recommended ANC care while 55 (78.6\%) literate women received minimum Recommended ANC care. Statistically significant association was seen between education of study subjects and utilization of recommended ANC care, similar findings were seen by C. S. Metgud et al., ${ }^{9}$ Pavalavalli Govindasamy et al. ${ }^{17}$ and Ofra Anson. ${ }^{18}$ Antenatal services usage was less in illiterate women than in literate women in study by $\mathrm{K}$. Navaneetham et al. ${ }^{19}$ however no association was seen by SP Zodpey et al. ${ }^{8} 68 \%$ women utilize ANC care exclusively from public health facility which is low as compared to $92 \%$ by Varma GR et al. ${ }^{20}$ while $32 \%$ women also visited to private hospitals which is low as compared to $54 \%$ by Varma GR et al. ${ }^{20}$ Weight was measured in 91 women during ANC visit.This is similar to findings by (93\%) S. P. Zodpey et al., ${ }^{8}$ however this was in contrast to findings by $(48.3 \%)$ Monica Agarwal et al. ${ }^{21}$ Height was measured in only 12 women during visit to sub centre or PHC, very low compared to findings by $(47.9 \%)$ S. P. Zodpey et al. $^{8}$ In a study by Monica agarwal et al., Height was not measured in single women. ${ }^{21}$ Blood pressure was recorded in 77 women in this study. In a study by Monica agarwal et al, blood pressure was not recorded in single women. ${ }^{21}$ In a study by S. P. Zodpey et al, Blood pressure was measured in almost all women. ${ }^{8}$

$57 \%$ women received information regarding breast feeding, similar findings seen a study conducted by SP Zodpey et al. ${ }^{8}$ and Monica Agarwal et al. ${ }^{21}$

Only 29\% women received information about contraception. However in a study conducted by SP Zodpey et al. $40.6 \%$ women received family planningrelated advice. ${ }^{8} 94 \%$ women received advice regarding place or person of delivery, which is fairly high compared to findings by Monica Agarwal et al. 10\% women got advice regarding place or person of delivery. ${ }^{21}$

Only $46 \%$ women were reminded of their next visits as compared to $58.3 \%$ in a study by Monica Agarwal et al. ${ }^{21}$ Only 11 women were asked about any questions or concerns regarding pregnancy during their ANC visit, however not a single woman were asked about the same in a study by Monica Agarwal et al. ${ }^{21}$ 
$64(87.7 \%)$ women who received recommended ANC care had institutional delivery. This shows that majority of women who received recommended ANC care had institutional delivery as compared to those women who did not received recommended ANC care. However in a study conducted by S. P. Zodpey et al., the preference for place of delivery was not significantly influenced by minimum recommended antenatal care. ${ }^{8}$

\section{CONCLUSION}

Socioeconomic class of study subject, age, education was determinants which were found to affect utilization of antenatal care. Percentage of registration during first trimester was less than average for rural area of Thane district DLHS-3 data in spite of various programmes like Janani Suraksha Yojana, Matrutva Anudan Yojana and NRHM are implemented in the area. There was lack of awareness and motivation in study subjects to come on their own to PHC for early registration of pregnancy. Though the coverage of ANC services was good it was not of good quality.

\section{Recommendations}

The low level of utilization of minimum recommended antenatal care among illiterate women suggest the need to improve the literacy status of women through adult literacy programme thereby empowering them to take well informed and appropriate decisions regarding their health while pregnant. As overall utilization of antenatal care is more among educated women. Illiterate women should be motivated consistently during antenatal visits and through home visits by ANM to (come to primary health centre)increase their utilization of antenatal services.

\section{Limitations of study}

It is possible that information regarding utilization, exact month of registration, number of visits and check- ups may not be fairly accurately recalled by the respondents. We could not validate the information given by the respondents as the records were either incomplete or poorly maintained.

\section{Acronyms and abbreviations}

MDG: Millennium development Goal

NFHS: National family health survey

ANC: Antenatal care

IFA: Iron folic acid

TT: Tetanus toxoid

PHC: Primary health centre

DLHS: District level household survey

SPSS: Statistical package for social sciences

ICTC: Integrated counselling and testing centre

VDRL: Venereal disease research laboratory

USG: Ultrasonography

PIH: Pregnancy-induced hypertension
OBC: Other backward classes

BP: Blood pressure

Funding: No funding sources

Conflict of interest: None declared

Ethical approval: The study was approved by the ethics committee of Seth G.S. medical college, Mumbai

\section{REFERENCES}

1. World Health Organization. Making pregnancy safer; millennium development goal 5, 2008. Available at: http://www.who.int/making_pregnancy_safer/topics/ mdg/en/index.html. Accessed 5 October 2008.

2. United Nations. The millennium development goals report, 2009. Available at: http://www.un.org/millenniumgoals/pdf/MDG_Repo rt_2009_ENG.pdf. Accessed 20 August 2009.

3. USAID, Focused Antenatal Care. Providing integrated, individualized care during pregnancy, 2014. Available at: www.accesstohealth.org.

4. Government of Maharashtra, Ministry of Health And Family Welfare, Primary Health Centre. Medical officer's training module, 2013. Available at: http://nrhm.gov.in/nrhm-in-state/state-wiseinformation/maharashtra.html.

5. IIPS District level household and facility survey under reproductive and child health project (DLHS3). In: IIPS, eds. Ministry of Health and Family Welfare, Government of India 2007-08. Mumbai: International Institute for Population Sciences; 2009.

6. Venkatesh RR, Umakantha AG, Yuvaraj J. Safe Motherhood status in the urban slums of Davangere city. Indian J Community Med. 2005 JanMar;30(1):6-7.

7. International Institute for Population Sciences (IIPS). National family health survey (NFHS-3), 2005-06. In: IIPS, eds. IIPS Survey. Mumbai: IIPS; 2007.

8. Khatib N1, Zahiruddin QS, Gaidhane AM, Waghmare L, Srivatsava T, Goyal RC, et al. Predictors for antenatal services and pregnancy outcome in a rural area: A prospective study in Wardha district, India. Indian J Med Sci. 2009 Oct;63(10):436-44.

9. Metgud CS, Katti SM, Mallapur MD, Wantamutte AS. Utilization patterns of antenatal services among pregnant women: a longitudinal study in rural area of North Karnataka. Al-Ameen J Med Sci. 2009;2(1):58-62.

10. Loveleen Sethi NK. Evaluation of quality of maternal and child health services at maternal and child welfare centre under the municipal corporation of Delhi. In: Loveleen Sethi NK, eds. A Thesis. New Delhi: NIHFW; 1997.

11. Toan K. Tran, Chuc TK. Nguyen, Hinh D. Nguyen, Bo Eriksson, Goran Bondjers, Karin Gottvall, et al. Urban - rural disparities in antenatal care utilization: a study of two cohorts of pregnant women in Vietnam. BMC Health Services Res. 2011;11:120. 
12. Emilia Goland, Dinh Thi Phuong Hoa, Mats Målqvist. Inequity in maternal health care utilization in Vietnam. Int J Equity Health. 2012;11:24.

13. Rajesh Gupta, Jagdish Mandliya, H. P. Singh. Assessment of maternal-fetal and neonatal healthcare practices in an eastern Madhya Pradesh district. Int J Med Sci Public Health. 2013;2(2):403-9.

14. Materia E, Mehari W. A community survey on maternal and child health services utilization in rural Ethiopia. Eur J Epidemiol. 1993 Sep;9(5):511-6.

15. Sahni B, Sobti S. Utilization of antenatal care among pregnant females registered at sub centre level in a rural area of Jammu in India. Int $\mathbf{J}$ Healthcare Biomed Res. 2013 Jul;1(4):269-78.

16. Bbaale E. Factors influencing the utilisation of antenatal care content in Uganda. Australas Med J. 2011;4(9):516-26.

17. Pavalavalli Govindasamy, B. M. Ramesh. Maternal education and the utilization of maternal and child health services in India. In: Pavalavalli Govindasamy, B. M. Ramesh, eds. National Family
Health Survey Subject Reports Number 5. India: National Family Health Survey; December 1997.

18. Ofra Anson. Utilization of maternal care in rural HeBei province, People's Republic of China: individual and structural characteristics. Health Policy. 2004 Nov;70(2):197-206.

19. Navaneetham K, Dharmalingam A. Utilization of maternal health care services in Southern India. Soc Sci Med. 2002;55(10):1849-69.

20. Varma GR, Kusuma YS, Babu BV. Antenatal care service utilization in tribal and rural areas in a South Indian district: an evaluation through mixed methods approach. J Egypt Public Health Assoc. 2011;86(12):11-5.

21. Monika Agarwal, M. Z. Idris. Quality of reproductive health care at primary level. Indian $\mathbf{J}$ Community Med. 2001;26(3):119-28.

DOI: $10.5455 / 2320-1770$. ijrcog20150418

Cite this article as: Bhaisare KA, Rao DH, Khakase GM. Study of utilization of antenatal care services in tribal area of Thane district. Int J Reprod Contracept Obstet Gynecol 2015;4:378-83. 